\title{
A INFLUÊNCIA DO ESTILO DE TRABALHAR EM GRUPO NOS PROCESSOS DE CONSTRUÇÃO DO CONHECIMENTO ORGANIZACIONAL
}

\section{THE INFLUENCE OF THE GROUP WORK STYLE IN THE CONSTRUCTION PROCESS OF THE ORGANIZATIONAL KNOWLEDGE}

\author{
Robson Luiz Montanari ${ }^{1}$; Luiz Alberto Pilatti ${ }^{2}$ \\ ${ }^{1}$ Universidade Tecnológica Federal do Paraná - UTFPR - Ponta Grossa - Brasil \\ prof robson@terra.com.br \\ ${ }^{2}$ Universidade Tecnológica Federal do Paraná - UTFPR - Ponta Grossa - Brasil \\ lapilatti@utfpr.edu.br
}

\begin{abstract}
Resumo
O presente estudo de caso objetivou, em sete equipes de uma empresa de médio porte, prestadora de serviços, identificar a influência do estilo de trabalhar em grupo nos processos de criação do conhecimento organizacional (CO). Foram feitas entrevistas, observações não-participantes e a aplicação de dois questionários para este estudo de caso. O primeiro é proposto por Parker (1994) e avaliou os estilos de trabalhar em grupo. O segundo foi elaborado tendo como base as atividades fundamentais para criação do CO de Leonard (1995) e avaliou a existência de processos de construção do CO. Os resultados evidenciam duas matrizes diferentes. A primeira com uma distribuição relativamente uniforme dos estilos nas equipes e médias que caracterizam um número maior de membros que não praticam as atividades para construção do CO; a segunda com predominância no estilo contribuinte e com médias que caracterizam um número maior de membros praticando as atividades essenciais para construção do CO. Tendo como base os resultados pode-se inferir que, dentre os estilos idealizados por Parker (1994), o estilo contribuinte é um dos estilos mais propícios e o desafiador um dos menos favoráveis para criação do conhecimento organizacional na empresa.
\end{abstract}

Palavras-chave: Equipes, Estilos de Trabalhar em Grupo e Conhecimento Organizacional.

\section{Introdução}

O ritmo das mudanças ultrapassou a capacidade de resposta da maioria das organizações. Forças inelutáveis como a globalização, a tecnologia, o crescimento e declínio em setores de trabalho criaram uma nova Era, a Era do Conhecimento. As ações empresariais voltadas para a inovação tecnológica e para competitividade fazem do conhecimento uma questão central, 
transformando o capital humano em um ativo estratégico responsável pela criação do conhecimento.

Essa realidade induz a mudança, especialmente ao impor a necessidade de que as empresas sejam mais inovadoras e empreendedoras. Em decorrência da necessidade de respostas rápidas, os recursos humanos tiveram seus papéis redesenhados dentro de um cenário absolutamente novo. $\mathrm{O}$ emprego tem deslocado o foco do processo de profissionalização do fazer para o saber fazer, de um trabalho individual em um posto específico para o trabalho coletivo.

Na visão de Claver-Cortés et al. (2007), o cenário é de mudanças e as empresas estão buscando nas estruturas mais flexíveis subsídios para superar as adversidades diárias e gerar novos conhecimentos. Para Sacomano e Escrivão Filho (2000), a abertura dos mercados para a concorrência internacional exigiu das empresas esforços significativos para atingir patamares competitivos. Bejarano (2006) destaca que a busca constante e incessante por melhorias na performance organizacional é uma realidade no atual ambiente de trabalho, pois as organizações são atualmente movidas pela competitividade da economia globalizada e pela crescente necessidade de aumento de produtividade.

Em se tratando de produtividade, complementa Bejarano (2006), as empresas estão buscando cada vez mais investir em equipes como parte da sua estrutura organizacional. Peter Drucker (2001) faz essa constatação e destaca que o trabalho em equipe não é bom nem desejável, é um fato. Sempre que as pessoas trabalham ou jogam em conjunto, elas o fazem em equipe. Outros autores como Chang (1999) e Katzenbach e Smith (2001) relatam que as equipes são fundamentais para o desempenho empresarial e podem ser utilizadas como resposta às mudanças organizacionais.

A necessidade de um entendimento mais abrangente do estilo de trabalhar em grupo é, diante da crescente utilização da gestão baseada em equipes, fundamental para formação e reestruturação de equipes no ambiente produtivo, que cada vez mais, necessita superar as adversidades diárias e gerar conhecimentos para resolução de problemas. O presente artigo tem como objetivo identificar a influência do estilo de trabalho coletivo nos processos de construção do conhecimento organizacional $(\mathrm{CO})$ em sete equipes de uma empresa de médio porte, prestadora de serviços, que utiliza a gestão de equipes em seu setor operacional.

\section{As Equipes e os estilos de Trabalhar Coletivamente}

Bejarano (2008) comenta que as literaturas comerciais influenciam as empresas a desenvolverem o trabalho em equipe, porém na prática observa-se que pouco se sabe sobre implantar ou utilizar equipes para obter o máximo desempenho conjunto. Para alguns autores como Robbins e Finley (1997) e Chang (1999), as equipes apresentam múltiplas vantagens, entretanto 
para autores, como Drucker (2001) e Moscovici (2003), a formação de equipes, embora apresentando vantagens, não passa de um clichê entre as empresas, pois equipes reais ainda são raras.

Uma idéia equivocada, e que talvez seja justamente a maior razão para o fracasso da formação de equipes, é a crença praticamente universal dos executivos na existência de apenas um tipo de equipe. Essa constatação foi feita por Drucker (2001). Para o autor, existem três tipos de equipes verdadeiras, "cada uma diferente em sua estrutura, no comportamento que exige de seus membros, nas suas forças, vulnerabilidade, limitações e exigências, mas acima de tudo naquilo que pode fazer e que deve ser usada" (DRUCKER, 2001, p. 59).

Drucker (2001) distingue os três tipos, considerando que as equipes se diferem no comportamento que exigem, naquilo que fazem melhor e no que não podem fazer. Os tipos de equipes são: a) os membros têm posições fixas e atuam na equipe, mas não em equipe, como uma equipe de beisebol ou uma linha de montagem; b) os membros têm posições fixas, mas atuam em equipe como em uma equipe de futebol, e c) os membros têm posições principais ao invés de fixas. Eles devem “cobrir” seus companheiros de equipe, ajustando-se quando necessário, como as duplas de tênis ou um conjunto de jazz.

Visões diferentes são compartilhadas por Fisher et al. (1997), Katzenbach (1999), Salomão (1999), Sacomano Neto e Escrivão Filho (2000) e Moscovici (2003) que relacionam o trabalho em equipe a objetivos comuns, ao compartilhamento de competências e de esforços. $\mathrm{O}$ fato de trabalharem em conjunto não dá aos grupos, independente das posições que seus membros ocupem (fixas ou não), o status de "equipe", contrariando o idear de Drucker (2001).

O raciocínio de Drucker (2001) proporciona o entendimento de uma situação que nem sempre é suficientemente clara, pois nem todos os grupos têm a mesma finalidade. Em linhas gerais, não existem justificativas para uma equipe de futebol "jogar" como uma dupla de tênis. Na primeira equipe existe a necessidade de trabalho interdependente, os "jogadores" dependem uns dos outros, enquanto na segunda, não. E também não existe justificativas para uma equipe de beisebol “jogar” como uma equipe de futebol, pois na primeira equipe o trabalho é na equipe e não em equipe.

Independente da conformação laboral, adotar ou não o formato de equipes, o trabalho coletivo é, na visão de Bejanano et al., (2005b), quase sempre involuntário e o comprometimento necessário pode estar ausente. Robbins e Finley (1997, p. 57) compartilham deste idear e inferem que as pessoas em equipe são "como as pessoas em qualquer outro lugar", ou seja, "têm seus altos e baixos".

Karakowsky et al. (2004) destacaram percepções e influências entre homens e mulheres trabalhando em equipes. O impacto estende, além do comportamento e dos sentimentos, as 
percepções a respeito dos esforços da equipe. Homens e mulheres podem alterar suas percepções na equipe baseando-se, por exemplo, na qualidade de esforços da sua equipe.

Não obstante, um fator interessante e que merece atenção é o estilo de trabalhar que cada pessoa pode apresentar no ambiente produtivo. Uma das técnicas na escolha de pessoas para compor uma equipe é, na visão de Aleixo (2003), fazer um balanceamento entre os membros que já possuem algumas habilidades com os que não possuem ou precisam desenvolver.

Armstrong (1997) e Bejarano et al. (2005b) vão além e citam a necessidade de selecionar melhor os membros para as equipes através de centros de avaliação especializados e de métodos que permitam identificar os perfis. Bejarano et al. (2005b, p. 8) menciona que "identificar os perfis de todos os membros de uma equipe pode ajudar a antecipar conflitos e desenvolver métodos de trabalho antes mesmo da manifestação de dificuldades entre os membros”. Para Parker (1994), quando as pessoas trabalham em grupo, elas podem ser classificadas em quatro estilos: contribuinte, colaborador, comunicador e desafiador.

O contribuinte é um participante orientado para a execução de tarefas, aprecia fornecer ao grupo informações de boa qualidade e insiste com o grupo para elevar seu desempenho. A maioria das pessoas enxerga o contribuinte como alguém em quem se pode confiar. Eventualmente se envolve demasiadamente com os detalhes e não consegue enxergar o todo. As pessoas descrevem o contribuinte como alguém responsável, autoritário, confiável, competente e organizado.

O colaborador é um participante orientado para o objetivo, pois dá maior importância para as metas e missões. A maioria das pessoas vê o colaborador como alguém que consegue enxergar o todo, mas que, às vezes, deixa de dar atenção às tarefas básicas do grupo. As pessoas descrevem o colaborador como alguém que enxerga a longo prazo, orientado para os objetivos, conciliador, flexível e imaginoso.

O comunicador é um participante orientado para o processo, capaz de ouvir bem e de facilitar a participação alheia, a resolução de conflitos, o consenso, o feedback e o desenvolvimento de uma atmosfera descontraída. A maioria das pessoas vê o comunicador como uma pessoa orientada a pessoas. O comunicador é considerado como alguém que não gosta de confronto e é descrito como aquele que apóia e tem consideração pelos outros, é descontraído, entusiasmado e cuidadoso nas relações pessoais.

O desafiador é um participante que questiona os objetivos, métodos e mesmo a ética do grupo. Tem predisposição para discordar do líder e incentiva o grupo a assumir riscos bem calculados. A maioria das pessoas aprecia o valor de sua franqueza e de sua mente aberta. Às vezes, o desafiador fica autoconfiante e pressiona demais os companheiros. O desafiador é descrito como alguém honesto, que gosta de falar diretamente, tem princípios, é ético e aventuroso. 
Uma pessoa pode ter diferentes estilos de trabalhar, porém um ou dois deles acabam prevalecendo na maioria do tempo. O estilo principal define um conjunto de comportamentos que será usado mais freqüentemente como participante de um grupo (PARKER, 1994).

Assim como em uma equipe de futebol, formada por atletas desempenhando papéis diferentes, todos os estilos, na visão de Parker (1994), são necessários para uma equipe, pois todos têm características que são úteis ao bom andamento dos trabalhos em um determinado momento. Thomaz e Kovaleski (2006, p. 180) consideram, utilizando a classificação de estilos de Parker (1994), "que os estilos contribuinte e comunicador são os melhores para que ocorra o compartilhamento do conhecimento tácito [...]”.

Embora todos os estilos tenham sua importância, alguns contribuem de maneira mais significativa para certas atividades no ambiente produtivo, de acordo com Thomaz e Kovaleski (2006). Bejarano (2005b) e Armstrong (1997) - que defendem a idéia de processos de seleção mais consistentes - relacionam este fator como sendo fundamental ao desempenho das equipes. "É possível que as diferentes personalidades acarretem mau funcionamento, mas, na maioria dos casos, se os integrantes tiverem o conjunto certo de habilidades complementares e se respeitarem mutuamente em função dessas habilidades, a personalidade de cada um não terá muita importância" (KATZENBACH 1999, p. 59).

A análise dos estilos de trabalhar coletivamente pode auxiliar as organizações no sentido de formar grupos ou equipes para atividades especificas ou para conseguir o equilíbrio ideal dos estilos e evitar possíveis problemas com confrontos de comportamentos e personalidades entre os membros no ambiente produtivo.

\section{As Equipes e os Processos para Construção do Conhecimento Organizacional}

Atualmente o conhecimento assume uma função importantíssima, pois as empresas passam a contar, além dos recursos que já são conhecidos como capital e mão-de-obra, com os conhecimentos aplicados ao trabalho e com os trabalhadores do conhecimento, denominados, segundo Drucker (2004), de knowledge worker.

Para Claver-Cortés et al. (2007), as empresas cada vez mais adotam projetos organizacionais flexíveis, estruturas com menos níveis hierárquicos a fim de permitir o diálogo entre equipes e, assim, incentivar a aprendizagem coletiva gerando novos conhecimentos. Em decorrência dessas mudanças, segundo Senge (1998), as equipes representam a unidade de aprendizado fundamental nas organizações modernas. Isto é, o conhecimento individual e estanque não interessa à organização. Aprendizagem organizacional é aprendizagem compartilhada a serviço dos objetivos da organização. 
Para Nonaka e Takeuchi (1997), a criação do conhecimento é um processo que ocorre dentro de uma comunidade de interação e que amplia organizacionalmente o conhecimento adquirido pelas pessoas. O conhecimento organizacional $(\mathrm{CO})$ passa a ser fruto das interações que ocorrem no território empresarial que, para Fleury e Oliveira (2001), é desenvolvido por meio de aprendizagem e é o fundamento das competências essenciais da organização formadas por conhecimentos tácitos e coletivos.

Davenport (1994) aponta o fato de que os conhecimentos interfuncionais das equipes facilitam a interface funcional e colaboram com a elaboração do planejamento, aumentando a probabilidade de que determinado produto atenda a exigências multifuncionais. Para Bejarano et al. (2005a), as equipes têm algumas limitações, entre elas a dificuldade de compartilhar conhecimentos entre os membros que, segundo Terra (2000), são limitações oriundas do ambiente que estão inseridas e que não propicia soluções de problemas e erros pessoais

Leonard (1995) infere que os processos de construção do conhecimento na empresa estão relacionados a quatro atividades, as quais são decisivas para construção do CO. São elas: compartilhamento da tarefa de análise e solução de problemas, envolvimento do cliente, experimentação e importação de conhecimentos. Tais atividades são evidenciadas na Figura 1, abaixo:

Figura 1 - Atividades para construção do conhecimento organizacional

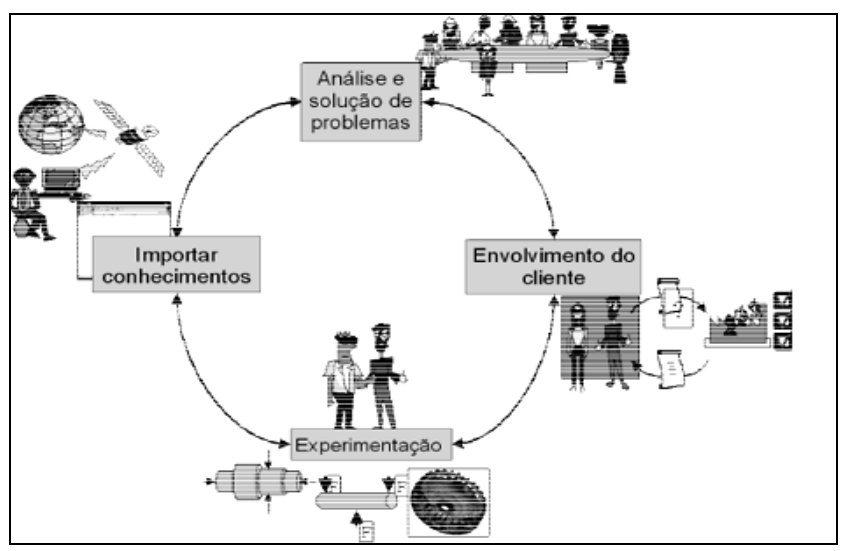

Fonte: Silva (2002, p. 143)

Para Silva (2002), que também discutiu as atividades propostas por Leonard (1995), a chave para construção do CO está na inter-relação das atividades. Para que haja o inter-relacionamento de uma atividade para com as demais, as mesmas precisam contemplar: 
a) o compartilhamento da tarefa de análise e solução de problemas, ou seja, a preocupação está em reunir visões diferentes para análise e participação de pessoas para confrontação construtiva;

b) o envolvimento do cliente, de um modo que ele participe das decisões através de consultas periódicas;

c) a existência de um clima que tolere a experimentação e a visualização de soluções por intermédio da prática, como uma forma de assegurar o aprendizado da organização;

d) a absorção de conhecimentos do mercado (importar conhecimentos), desde a observação informal de alguma fonte, a realização de benchmarking, até a realização de alianças e jointventures.

As atividades propostas por Leonard (1995) estão intimamente ligadas à reunião de pessoas com características diferentes buscando a confrontação construtiva (creative abrasion). $\mathrm{O}$ aprendizado em grupo é o processo de desenvolvimento da capacidade de um grupo criar os resultados que seus membros realmente desejam (SENGE, 1998). Esse aprendizado possui três dimensões essenciais:

a) a necessidade de analisar com discriminação as questões complexas tornando a inteligência do grupo maior que a individual;

b) a necessidade de ações inovadoras oriundas das contribuições de todos;

c) a ligação de um grupo com outros grupos para troca de conhecimentos.

O aprendizado coletivo vem ao encontro das atividades expostas por Leonard (1995), já que os grupos ou equipes passam a aprender pelo trabalho e pela prática das atividades. Para Nonaka e Takeuchi (1997, p. 79), “a criação do conhecimento organizacional é uma interação contínua e dinâmica entre o conhecimento tácito e o conhecimento explícito", ou seja, entre o conhecimento intangível que está dentro das pessoas e o tangível, formal e documentado.

Com efeito, o desafio para as organizações está em mudar a cultura já existente de modo a se criar um clima propício à mudança e ao aprendizado, pela interação dos conhecimentos tácitos e explícitos. Quando essa mudança ocorre, geram-se conhecimentos e se origina uma interação contínua e dinâmica entre eles. É a denominada Espiral do Conhecimento (NONAKA; TAKEUCHI, 1997). 
Figura 2 - Espiral do conhecimento

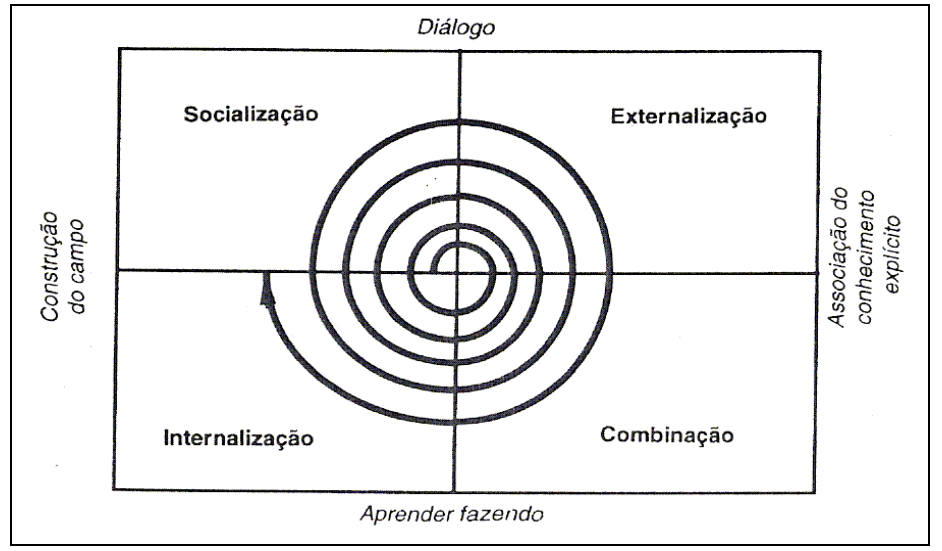

Fonte: Nonaka e Takeuchi (1997, p. 80)

São os padrões básicos para a criação do CO, descritos por Nonaka e Takeuchi (1997) como:

a) socialização: tácito em tácito - criação de conhecimento pela da observação, pela prática, pelo compartilhamento de experiências;

b) externalização: tácito em explícito - criação de conhecimento pela articulação do conhecimento tácito e sua transformação em conhecimento explícito;

c) combinação: explícito em explícito - criação de conhecimento pela combinação de dados, informações e conhecimentos;

d) internalização: explícito em tácito - criação de conhecimento pela comunicação de conhecimentos explícitos que são absorvidos pelas pessoas, entendidos e traduzidos em conhecimento tácito.

A seqüência completa das atividades de Nonaka e Takeuchi (1997) e Leonard (1995) propiciam, na visão de Silva et al. (2005, p. 4791), a construção do conhecimento e havendo "efetivamente um aproveitamento adequado e satisfatório do conhecimento gerado podendo este vir a promover inovações a partir de sua aplicação".

Neste contexto, Moscovici (2003) relata que a implantação e desenvolvimento de equipes vêm ao encontro da necessidade de as organizações mudarem a cultura existente. Assim também Leuch et al. (2005), ao analisarem as barreiras culturais para a gestão do conhecimento, enfatizam que os recursos humanos têm papel fundamental para se superarem resistências e mudarem a cultura organizacional.

Tomando como base Sacomano e Escrivão Filho (2000), Katzenbach e Smith (2001) e Drucker (2001), que enfatizam a presença das equipes na estrutura organizacional, e Szezerbicki (2006), que analisou a gestão do conhecimento em equipes de alta performance, pode-se inferir que as equipes auxiliam a organização criando um ambiente adequado à mudança, pois os membros 
estão envolvidos em um processo que possibilita a prática de atividades voltadas ao aprendizado e ao desenvolvimento de novas habilidades.

\section{Metodologia}

Os procedimentos prescritos por Yin (2001), adaptados ao caso em exame, foram seguidos por se tratar de um método a ser utilizado em uma investigação empírica de um fenômeno dentro de seu contexto da vida real. Em termos práticos, observou-se as seguintes etapas: a) revisão bibliográfica; b) elaboração de entrevista semi-estruturada composta de questões abertas e com roteiro para condução da mesma; c) definição da população; d) entrevista; e) elaboração de questionário para apurar a existência de processos de construção do conhecimento organizacional (CO); f) observação não-participante; g) aplicação do questionário; h) aplicação do instrumento de Parker (1994) para apurar o estilo de trabalhar em grupo dos membros das equipes, e i) análise dos dados e resultados.

A empresa em estudo é uma empresa prestadora de serviços, de médio porte, que atua no transporte de passageiros em linhas rodoviárias e metropolitanas no estado do Paraná, turismo, fretamentos e viagens no Brasil e países do Mercosul e de logística no estado do Paraná.

O questionário foi composto de quatro questões tendo como base as atividades essenciais para construção do CO abordadas por Leonard (1995). O instrumento é composto por 18 questões, nas quais os respondentes distribuíram em cada questão até a nota 4 para situação que mais se aplica e até a nota 1 para a que menos se aplica no trabalho presencial na equipe que pertence.

A população foi composta de um universo de quatro gerentes e de 75 membros de equipes da empresa em estudo. Dois membros de equipe foram descartados, pois estavam participando da primeira reunião em suas equipes e entendeu-se que os mesmos não tinham experiência prática para responder os questionários.

A entrevista semi-estruturada foi aplicada a quatro gerentes da empresa. O objetivo da entrevista com um dos entrevistados foi de caráter exploratório; com os demais o objetivo foi verificar a existência de processos que levem a construção do $\mathrm{CO}$ a partir das equipes. Os entrevistados receberam a sigla $\mathrm{D}$ (declarantes) e foram numerados com algarismos arábicos a fim de preservar a identidade dos mesmos. Buscando melhorar a interpretação das respostas e dos registros na entrevista, utilizou-se, com a autorização dos entrevistados, um gravador e transcritas ipsis literis as respostas.

Em seguida, o questionário elaborado e o instrumento proposto por Parker (1994) foram aplicados aos membros das equipes. Juntamente com a aplicação dos mesmos, as observações de caráter não-participante foram feitas. Os membros das equipes responderam ao questionário e aos 
instrumentos identificando somente a equipe a que pertence. As equipes receberam a sigla $\mathrm{E}$ (equipe) e foram numerados com algarismos arábicos. Os gerentes responderam ao questionário sem se identificar. Em seguida, membros de equipes e gerentes depositaram os mesmos em urnas a fim de assegurar sigilo sobre suas opiniões e, também, estabelecer um clima de confiança e empatia (TRIVIÑOS, 1987).

Para análise dos dados obtidos utilizou-se a técnica de triangulação sugerida por Triviños (1987) que em linhas gerais consiste no emprego de diferentes evidências para busca de uma resposta mais aprofundada. Segundo Yin (2001, p. 121), "várias fontes de evidências fornecem essencialmente várias avaliações do mesmo fenômeno". Os procedimentos tiveram a intenção de aumentar a compreensão dos dados para análise e conclusões dos resultados.

Para análise das entrevistas foi utilizada a análise de conteúdo que, segundo Minayo (2004), busca encontrar respostas para confirmar as hipóteses. Para tanto foram organizados as entrevistas por categorias de acordo com o referencial teórico para facilitar os processos de triangulação dos dados. Os questionários receberam análise estatística. Os resultados da aplicação do instrumento foram transferidos para o quadro de resultados e identificado os estilos que mais predominaram seguindo as orientações de Parker (1994).

Após análise dos dados individualmente os mesmos foram confrontados. Essa confrontação buscou, segundo Yin (2001), as generalizações. As generalizações estatísticas por meio da inferência sobre a população definida; e as analíticas pela comparação dos dados empíricos com a teoria.

\section{Resultados e Discussões}

As experiências pessoais e profissionais criam uma personalidade nas pessoas que, no trabalho em equipe ou em outro qualquer, trabalham num continuum interagindo com o ambiente que está inserido. Formar grupos ou equipes de trabalho com o equilíbrio ideal de personalidades ou estilos torna-se fundamental diante da crescente utilização da gestão baseada em equipes retratada por inúmeros autores: Claver-Cortés et al. (2007), Bejarano (2006), Drucker (2001) e Sacomano e Escrivão Filho (2000).

A Tabela 1 quantifica a predominância de estilos entre os membros das equipes em estudo mostrando o número de vezes que o estilo predominou nas mesmas a partir da aplicação do instrumento proposto por Parker (1994). 
Tabela 1 - Estilo de trabalhar em grupo

\begin{tabular}{c|c|c|c|c}
\cline { 2 - 5 } & Contribuinte & Colaborador & Comunicador & Desafiador \\
\cline { 2 - 5 } & \multicolumn{2}{|c|}{ Número de vezes que o estilo predominou na equipe } \\
\hline Equipe 1 & 7 & 4 & 3 & 0 \\
\hline Equipe 2 & 9 & 2 & 5 & 1 \\
\hline Equipe 3 & 5 & 4 & 4 & 2 \\
\hline Equipe 4 & 4 & 5 & 3 & 5 \\
\hline Equipe 5 & 5 & 5 & 4 & 5 \\
\hline Equipe 6 & 4 & 4 & 3 & 2 \\
\hline Equipe 7 & 7 & 1 & 1 & 16 \\
\hline TOTAIS & 41 & 25 & 23 & \\
\hline
\end{tabular}

Fonte: os autores

Observa-se que, no geral, o estilo predominante entre os membros das equipes foi o contribuinte, em seguida, colaborador, comunicador e, por último, o estilo desafiador. Segundo Parker (1994), um membro de equipe pode ter diferentes estilos de trabalhar e prevalecer um ou dois que definem um conjunto de comportamentos. Na visão de Parker (1994) é possível dizer que os dois estilos que predominaram - contribuinte e colaborador - são os que dão uma maior atenção ao desempenho do grupo ou equipe.

Os resultados das equipes em estudo evidenciam matrizes diferentes de resultados em relação ao estilo de trabalhar em grupo. Os resultados das equipes 3, 4 e 6 aparecem de maneira mais uniforme, não apresentando tanta disparidade quanto nas equipes 1,2, 5 e 7, que apresentam mais membros com estilo contribuinte e menos com o desafiador.

Esses resultados, segundo Robbins (1999), Katzenbach e Smith (2001), Moscovici (2003) e Bejarano (2006), não são os ideais, pois equipes eficazes necessitam de habilidades complementares entre os membros. Na visão de Bejarano (2005b), o "equilíbrio de funções e personalidades" é fundamental "para que a equipe possa atingir seu potencial". A disparidade da predominância de estilos equipes 1, 2, 5 e 7 reflete, também, a política de recrutamento e seleção utilizada pela empresa que, segundo o entrevistado D1, visa somente conhecer algumas habilidades profissionais dos candidatos.

A atual política de formação das equipes na empresa em estudo vem ao encontro com o que Aleixo (2003) aborda: fazer um balanceamento entre os membros que já possuem algumas habilidades e os que precisam desenvolver as mesmas. Armstrong (1997) e Bejarano et al. (2005b) inferem que um processo de seleção mais amplo, contemplando a busca de mais características dos candidatos pode colaborar no sentido de possibilitar as organizações no desenho da equipe ideal. 
Os resultados do questionário com a função de apurar a existência de processos que indiquem a construção do conhecimento organizacional (CO) a partir das equipes em estudo são resumidos na Tabela 2 abaixo:

Tabela 2 - Processos de construção do conhecimento organizacional nas equipes

\begin{tabular}{|c|c|c|c|c|c|c|c|}
\hline \multirow[t]{2}{*}{ ATIVIDADES ESSENCIAIS } & $\underset{\tilde{\Xi}}{\vec{\Xi}}$ & 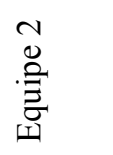 & 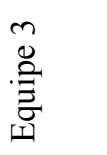 & 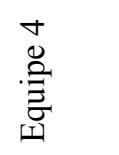 & 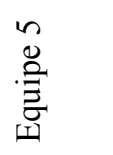 & $\begin{array}{l}0 \\
0 \\
\stackrel{O}{Z} \\
\underset{\Xi}{\Xi}\end{array}$ & 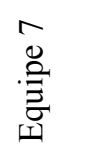 \\
\hline & \multicolumn{7}{|c|}{$\%$ RESPOSTAS POSITIVAS } \\
\hline 1 - Análise e soluções dos problemas. & 72,72 & 100,00 & 77,78 & 81,82 & 72,72 & 81,82 & 83,33 \\
\hline 2 - Envolvimento do cliente. & 100,00 & 63,64 & 88,89 & 100,00 & 100,00 & 81,82 & 66,66 \\
\hline 3 - Experimentação & 72,72 & 63,64 & 55,56 & 45,45 & 72,72 & 18,18 & 100,00 \\
\hline 4 - Importar conhecimentos. & 100,00 & 100,00 & 77,78 & 72,72 & 90,90 & 54,54 & 83,33 \\
\hline MÉDIA POR EQUIPE & 88,63 & 81,81 & 75,00 & 75,00 & 84,08 & 59,09 & 83,33 \\
\hline
\end{tabular}

Fonte: Os autores (2009).

Observa-se na Tabela que nas quatro atividades proposta por Leonard (1995) - 1-análise de problemas, 2-envolvimento do cliente, 3-experimentação e 4-importar conhecimentos - existem membros de equipes que discordam da prática delas no trabalho em equipe. Embora os resultados apontem a prática das quatro atividades pelas equipes, precisa-se considerar a presença de membros que acreditam não estar praticando as atividades essenciais para construção do CO. Somente em algumas atividades e em algumas equipes cem por cento dos respondentes concordam que a equipe pratica as atividades que são necessárias para construção do $\mathrm{CO}$.

As respostas negativas podem estar associadas a inúmeros fatores, mas um fator relevante, segundo Terra (2000), é que as pessoas em seus processos criativos e de aprendizado dependem de grande motivação intrínseca e de interação com outros. Assim pode-se estimular comportamentos favoráveis a resolução de tensões internas e permitir tentativas de erros pessoais.

Para Bejarano et al. (2005a) apesar das potencialidades das equipes estas têm algumas limitações que nem sempre são superáveis. Entre as limitações estão a dificuldades de conciliar a inclinação individualista com a disposição para trabalhar por um objetivo comum e a dificuldade de compartilhar conhecimento entre os membros e com os membros de outras equipes dentro das empresas.

Tomando como base a visão de Terra (2000) e Bejarano et al. (2005a), pode-se inferir que os grupos e as equipes no ambiente produtivo necessitam da interação e do compartilhamento dos conhecimentos tácitos e coletivos para que estas possam auxiliar as organizações nos processos de construção do CO. Neste contexto, Senge (1998) afirma que a aprendizagem em equipe é vital, se as mesmas não tiverem capacidade de aprender, a organização também não terá. 
As reuniões das equipes mostraram-se um ambiente favorável para que a aprendizagem coletiva se desenvolva. Durante as observações não-participantes verificou-se a prática das atividades essenciais para construção do CO. Essas atividades se assemelham às atividades propostas por Nonaka e Takeuchi (1997). É nas reuniões que acontece o compartilhamento de experiências (socialização), o registro dos conhecimentos e informações em atas (externalização) e a troca de conhecimentos (combinação). É a partir do trabalho diário que se efetiva a incorporação dos conhecimentos explícitos no conhecimento tácito (internalização).

A prática dessas atividades é percebida, também, durante a entrevista com os gerentes operacionais. O declarante $\mathrm{D} 4$, ao responder se os membros das equipes estavam aprendendo com o trabalho em equipe, posicionou-se da seguinte forma: "Eu acredito que não só entre eles, mas também entre nós [...]". O declarante D3 acredita que os membros das equipes estão “[ [...] mudando a forma de pensar e [...] estão absorvendo novos conhecimentos em cima disso. No entanto, pode-se observar novamente que existem membros de equipes que não praticam ou não colaboram com as atividades para criação do $\mathrm{CO}$ nas equipes. Isso pode ser percebido em fragmentos das respostas à pergunta sobre as decisões tomadas em equipe e a prática das mesmas:

a) 'Estão, mas é 'que nem eu tava' te falando agora, um pouco devagar, em alguns casos um se adianta, 'um sobressai' sobre o outro [...]" (D2);

b) “A maioria deles 'tão' fazendo isso, mas tem pessoas ainda que não ‘tão' fazendo [...]” (D3). Os resultados caracterizam a existência de um problema que pode ser decisivo para criação do CO na empresa. Sem a interação entre o conhecimento tácito e o explícito não há condições para que ocorra o processo em espiral proposto por Nonaka e Takeuchi (1997). Para Nonaka e Takeuchi (1997, p. 83), as "atividades em grupo", a "criação e o acúmulo de conhecimento em nível individual" estão associados à criação de um clima coletivo e colaborativo que desencadeará no $\mathrm{CO}$.

Em relação ao estilo de trabalhar em grupo e as atividades essenciais para construção do CO, pode-se observar que as equipes com distribuição mais uniforme dos estilos (Equipes 3, 4 e 6) apresentam a menor média (Tabela 2), indicando a presença de um número maior de membros que não concordam que a equipe pratique as atividades propostas por Leonard (1995). Nota-se que as equipes em que a predominância de um estilo teve mais disparidade (Equipes: 1, 2, 5 e 7) e apresentam a maior média (Tabela 2). Esses resultados indicam a presença de um número maior de membros que concordam, a equipe pratica as atividades essenciais para construção do $\mathrm{CO}$. Na prática isto significa que as equipes pautadas pela diversidade de estilos - segundo Bejarano (2006), Moscovici (2003) e Katzenbach e Smith (1994), a diversidade de estilos e perfis é uma característica de equipe eficaz - não estão realmente praticando as atividades necessárias para construção do CO. 
Os resultados das equipes $1,2,5$ e 7, que são compostas com mais membros com o estilo contribuinte, são convergentes com os resultados encontrados por Thomaz e Kovaleski (2006, p. 180), que consideram: “os estilos contribuinte e comunicador são os melhores para que ocorra o compartilhamento do conhecimento tácito [...]”. Na visão de Parker (1994) não há um melhor estilo, pois todos são necessários ao grupo ou equipe. Contudo, cada estilo define comportamentos que serão utilizados freqüentemente e que serão úteis em algum momento. Pode-se inferir que o momento, mencionado por Parker (1994) anteriormente, é mais favorável ao estilo contribuinte que predominou 41 vezes e está presente nas equipes que apresentam as melhores médias em relação a prática das atividades essenciais para construção do CO.

Os resultados de Thomaz e Kovaleski (2006) são melhores percebidos nas equipes 1, 2 e 5 que apresentam as melhores médias (Tabela 2) e a maior predominância dos estilos contribuinte e comunicador. Essas equipes, também, exibem a menor predominância, entre as equipes em estudo, do estilo desafiador. Este estilo tem maior predominância nas equipes 3, 4 e 6 as quais apresentam a menor média (Tabela 2) em relação a prática das atividades essenciais para construção do CO.

E, por fim observa-se na Tabela 2 que as melhores médias são das equipes 1 e 5 em que os perfis que mais predominaram foram o contribuinte e o colaborador. Esses resultados indicam que o estilo colaborador, assim como o contribuinte, também pode ser considerado um "bom" perfil para que ocorra o compartilhamento do conhecimento.

\section{Conclusões}

Os resultados deste estudo de caso permitiram identificar a influência do estilo de trabalhar em grupo nos processos de construção do conhecimento organizacional (CO) das equipes em exame. $\mathrm{O}$ estilo que predominou nas equipes - que melhor contribuiu para construção do $\mathrm{CO}$ - foi o estilo contribuinte, pautado pelo compartilhamento de informações.

O primeiro implicativo que caracteriza esta influência é mostrado com a distribuição de estilos nas equipes. As equipes com melhor distribuição dos estilos apresentam um número maior de membros que não concordam que a equipe pratique as atividades necessárias para construção do CO. As equipes que não têm uma distribuição tão uniforme, onde o estilo contribuinte predominou, apresentaram uma média que caracteriza a pratica das atividades essenciais para construção do CO.

O segundo implicativo que caracteriza a influência é percebido nas reuniões das equipes. Embora todas as equipes façam a socialização dos conhecimentos, a externalização a partir dos registros em atas, a combinação com a troca de conhecimentos e a internalização com a incorporação dos conhecimentos, existem equipes em que a presença de membros que não 
acreditam na prática dessas atividades é maior. Indicando a influência dos estilos na construção do $\mathrm{CO}$.

Pode-se considerar que o estilo contribuinte é um dos mais propícios e o desafiador um dos menos favoráveis para o compartilhamento e criação do conhecimento, entretanto não são elementos a serem observados de forma isolada. A política de recrutamento e seleção da organização precisa considerar não somente algumas habilidades profissionais, mas sim o estilo de trabalhar em grupo que o candidato apresenta. Essa observação pode auxiliar na configuração e a reconfiguração de equipes no ambiente produtivo. A necessidade de considerar o ambiente. $\mathrm{O}$ ambiente precisa proporcionar um clima favorável ao compartilhamento e a prática das atividades para criação do conhecimento organizacional. Os envolvidos precisam participar de um processo que possibilite o exercício de atividades voltadas ao aprendizado e o desenvolvimento de novas habilidades.

\begin{abstract}
The present case study planned to identify the influence of the group work style in the creation process of the organizational knowledge in seven teams of a medium-sized company in the services area. Interviews, non-participant observations and the application of two questionnaires were done for this study. The first is proposed by Parker (1994) and assessed the styles of working together. The second was developed based on the core activities to create knowledge of Leonard (1995) and evaluated the existence of processes of construction of organizational knowledge. The results show two different arrays. The first team had a relatively uniform distribution of the styles and was composed by a bigger number of members who do not believe they are practicing activities for the construction of the organizational knowledge; the second team had predominance in the contributing style with a lower number of members who do not believe. Based on the results, it is possible to infer that, among Parker's styles (1994), the contributing style is one of the most favorable and the challenging one, one of the least, for the knowledge sharing.
\end{abstract}

Key-words: Teams, Organizational Knowledge and Group Work Styles.

\title{
Referências
}

ALEIXO, A. I. S. Procedimentos para Implantar Equipes. 2003. 111f. Dissertação (Mestrado em Engenharia da Produção) - Programa de Pós-Graduação em Engenharia de Produção, UFSC, Florianópolis.

ARMStrong, A. Using Assessment Centers to Select Team Leaders. Asia Pacific Journal of Human Resources, p. 35-67.1997.

BEJARANO, V. C. Elementos Essenciais à Implementação de Equipes: um estudo de caso da indústria de papel. 2006. 115f. Dissertação (Mestrado em Engenharia da Produção) - Programa de Pós-Graduação em Engenharia de Produção, UTFPR, Ponta Grossa.

BEJARANO, V. C; PILATTI, L. A. Elementos Externos Essenciais à Implementação de Equipes: estudo de caso. Revista de Administração da Universidade de São Paulo. São Paulo, jan./fev./mar. v. 43. n. 1. p. 17-29, 2008.

BEJARANO, V. C. et al. Equipes e Comunidades de Prática como Estruturas Complementares na Gestão do Conhecimento Organizacional. In: Encontro Nac de Eng de Produção, XXV, 2005, Porto Alegre. Anais ... Porto Alegre: ABEPRO, 2005a. p. 4851-4856. 
BEJARANO, V. C. et al. Como Formar Equipes com Equilíbrio Ideal de Personalidades e Perfis Pessoais: a teoria e as ferramentas de Meredith Belbin. In: Congresso Brasileiro de Ensino de Engenharia, XXXIII, 2005, Campina Grande. Anais ... Campina Grande: Universidade Federal de Campina Grande-UFCG, 2005b. p. 1-12..

CHANG, R. Y. Construindo uma Equipe de Sucesso. São Paulo: Futura, 1999.

CLAVER-CORTÉS, E. et al. Organizational Structure Features Supporting Knowledge Management Processes. Journal of Knowledge Management. v. 11. n. 4. p. 45-57. 2007.

cross ${ }^{\text {ref }}$

DAVENPORT, T. H. Reengenharia de Processos: como inovar na empresa através da tecnologia da informação. 2 . ed. Rio de Janeiro: Campus, 1994.

DRUCKER, P. Administrando em Tempos de Grandes Mudanças. 5. ed. São Paulo: Pioneira Thomson Learning, 2001.

DRUCKER, P. Peter Drucker na Prática. Rio de Janeiro: Elsevier, 2004.

FISHER, S. G. et al. Team or Group? Managers' perceptions of the differences. Journal of Managerial Psychology. v. 12. n. 4. p. 232-242. 1997.

cross ${ }^{\text {ref }}$

FLEURY, M.T.L.; OLIVEIRA, M. M. J. Gestão Estratégica do Conhecimento: integrando aprendizagem, conhecimento e competências. São Paulo: Atlas, 2001.

LEONARD, D. Wellspring of Knowledge. Boston: Harvard Business School, 1995.

LEUCH, V. et al. Barreiras Culturais à Gestão do Conhecimento em Indústrias de Grande Porte dos Campos Gerais no Estado do Paraná: um enfoque na percepção dos funcionários. In: Encontro Nac de Eng de Produção, XXV., 2005, Porto Alegre. Anais ... Porto Alegre: ABEPRO, 2005. p. 4829-4836.

MINAYO, M. C. S. Pesquisa Social: teoria, método e criatividade. 23. ed. Petrópolis: Editora Vozes, 2004.

MOSCOVICI, F. Equipes dão Certo: a multiplicação do talento humano. 8. ed. Rio de Janeiro: José Olympio, 2003.

NONAKA, I.; TAKEUCHI, H. Criação de Conhecimento na Empresa. Tradução: Ana Beatriz Rodrigues e Priscila Martins Celeste. 12. ed. Rio de Janeiro: Elsevier, 1997.

PARKER, G. M. Team Players and Teamwork. São Paulo: Pioneira, 1994.

KARAKOWSKY, L. et al. Perceptions of Team Performance: the impact of group composition and task-based cues. Journal of Managerial Psychology. v. 19. n. 5. p. 506-525. 2004.

cross ${ }^{\text {ref }}$

KATZENBACH, J. A Disciplina das Equipes. HSM-Management. São Paulo, n. 17, nov-dez, p. 56-60, 1999.

KATZENBACH, J. R.; SMitH, D. K. A Força e o Poder das Equipes. São Paulo: Makron, 1994.

KATZENBACH, J. R.; SMITH, D. K. Equipes de Alta Performance: conceitos, princípios e técnicas para potencializar o desempenho das equipes. 6. ed. Rio de Janeiro: Campus, 2001.

ROBBINS, S. P. Comportamento Organizacional. 8. ed. Rio de Janeiro: LTC, 1999.

ROBBINS, H.; FINLEY, M. Por que as Equipes não Funcionam?. Rio de Janeiro: Campus, 1997.

SACOMANO N. M.; ESCRIVAO Filho, E. Estrutura organizacional e equipes de trabalho: estudo da mudança organizacional em quatro grandes empresas industriais. Gestão \& Produção, São Carlos, Ago, v. 7, n. 2, p.136-145, 2000 . 
SAlOMÃO, M. A. Desenvolvimento de Equipes. In: BOOG, G. G. [org.] Manual de Treinamento e Desenvolvimento. Associação Brasileira de Treinamento e Desenvolvimento. 3. ed. São Paulo: Makron Books, 1999. Cap. Desenvolvimento de Equipes. p. 507-532.

SENGE, P. A Quinta Disciplina: arte e prática da organização que aprende. 3. ed. São Paulo: Best Seller, 1998.

SILVA, S. L. Informação e Competitividade: a contextualização da gestão do conhecimento nos processos organizacionais. Ciência da Informação, maio/ago, vol.31, no.2, p.142-151. 2002.

SZEZERBICKI, A. S. a Gestão do Conhecimento em Equipes de Alta Performance: o caso do Clube Atlético Paranaense. 2006. 137f. Dissertação (Mestrado em Engenharia da Produção) - Programa de Pós-Graduação em Engenharia de Produção, UTFPR, Ponta Grossa.

TERRA, J. C. C. Gestão do Conhecimento: o grande desafio empresarial. São Paulo: Negócio, 2000.

TOMAZ, M. S.; KOVALESKI, J. L. Aspectos Sobre Compartilhamento de Conhecimento Tácito e Estilos de Trabalho em Equipe: um estudo de caso em uma empresa de energia elétrica. In: OLIVEIRA, M. R. et al. [orgs.] Gestão Estratégica para a Competitividade. Ponta Grossa: Editora UEPG, 2006. Cap. Gestão do Conhecimento e Inovação, p. 173-184.

TRIVIÑOS, A. Introdução à Pesquisa em Ciências Sociais. São Paulo: Atlas, 1987.

YIN, R. K. Estudo de Caso: planejamento e métodos. 2. ed. Porto Alegre: Bookman, 2001.

\section{Dados dos autores:}

1-Nome completo: Robson Luiz Montanari

Filiação institucional: Universidade Tecnológica Federal do Paraná - Campus de Ponta Grossa

Departamento:

Função ou cargo ocupado:

Endereço completo para correspondência (bairro, cidade, estado, país e CEP): Rua Xingú, 233 - ap 704 - Centro - Pato Branco - Paraná - Brasil - 85501-230.

Telefones para contato: 4688020129

e-mail: prof robson@terra.com.br

2-Nome completo: Luiz Alberto Pilatti

Filiação institucional: Universidade Tecnológica Federal do Paraná - Campus de Ponta Grossa

Departamento: PPGEP

Função ou cargo ocupado: Professor vinculado aos cursos de graduação em Engenharia de Produção e Programas de Pós-Graduação em Engenharia

Endereço completo para correspondência (bairro, cidade, estado, país e CEP): Av Monteiro Lobato, s/n km 4 - Ponta Grossa - Paraná - Brasil - 84016-210

Telefones para contato: 4232204805

e-mail: lapilatti@utfpr.edu.br 